Int. J. Electrochem. Sci., 14 (2019) $8676-8685$

International Journal of

ELECTROCHEMICAL

SCIENCE

$\underline{\text { WWW.electrochemsci.org }}$

\title{
Identification of Two Hetero-Substituent-Aromatic Isomers of - 4- and 7-Hydroxy Coumarin with the Belousov-Zhabotinsky Oscillator
}

\author{
Muhammad Yasir Nawabi ${ }^{1}$,Waqar Uddin ${ }^{1}$, Gang Hu ${ }^{1 \& 2^{*}}$, Saif Ullah ${ }^{1}$, \\ Zhaohui Fang ${ }^{3}$ and Saira Sardar \\ ${ }^{1}$ Department of Chemistry, Anhui University, Hefei, 230601, People's Republic of China \\ ${ }^{2}$ Anhui Province Key Laboratory of chemistry for Inorganic/Organic Hybrid Functionalized Materials \\ ${ }^{3}$ The First Affiliated hospital of Anhui University of Chinese Medicine, Hefei, 230031, P. R. China. \\ ${ }^{4}$ Institute of Chemical Sciences, University of Peshawar, Pakistan \\ *E-mail: hugang@ustc.edu
}

doi: $10.20964 / 2019.09 .08$

Received: 8 May 2019 / Accepted: 17 June 2019 / Published: 31 July 2019

In this article, we presented an innovative work of distinguishing the two different positional heterosubstituents-aromatic isomers i.e. 4-hydroxycoumarin (4-HC) and 7-hydroxycoumarin (7-HC) on their perturbation effect by a novel analytical Belousov-Zhabotinskii (BZ) oscillator. In such BZ oscillator, the tetra-aza-macrocyclic copper complex $\left([\mathrm{CuL}]\left(\mathrm{ClO}_{4}\right)_{2}\right)$ was used in which the ligand $\mathrm{L}$ is 5,7,7,12,14,14-hexamethyl-1,4,8,11-tetraeazacyclotetradeca-4,11 diene. Experimental data confirmed that, by discrete injection of these two isomers (4-HC and 7-HC) into the active BZ system with equal concentrations reflected in their inhibition time $\left(t_{\text {in }}\right)$, but the $t_{\text {in }}$ produced by $4-H C$ was higher than the $t_{\text {in }}$ initiated by $7-\mathrm{HC}$. The interesting feature is that, with increasing concentrations $\left(9.0 \times 10^{-5}\right.$ to $3.6 \times 10^{-}$ ${ }^{4}$ ) of 4-HC constantly increase the tin and decreased the oscillation number $(\mathrm{N})$ after the regeneration of oscillation. Whereas, the upsurge concentrations of 7-HC didn't change the tin but reduced the $\mathrm{N}$ after regeneration of oscillation. Thus, the two isomers were identified. Based on the mechanistic approach of FKN (Field-Koros-Noyes) model, the reaction perturbation mechanism was discussed. A fleeting description is that both 4-HC and 7-HC isomers were oxidized by $\mathrm{BrO}_{2}^{\bullet}$ intermediate radical (which produce during the course of reaction) into salicylic acid and quinone respectively and the system was temporary freeze $\left(\mathrm{t}_{\mathrm{in}}\right)$ as well. The products (salicylic acid and quinone) were identified by infra-red and Ultra-Visible spectroscopies.

Keywords: Belousov-Zhabotinsky; Chemical Oscillation; Isomers Identification; Hydroxycoumarin; Intermediate Species; Perturbation effect

\section{FULL TEXT}


(C) 2019 The Authors. Published by ESG (www.electrochemsci.org). This article is an open access article distributed under the terms and conditions of the Creative Commons Attribution license (http://creativecommons.org/licenses/by/4.0/). 